\title{
Enriched expression of NF1 in inhibitory neurons in both mouse and human brain
}

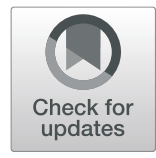

Hyun-Hee Ryu ${ }^{1,2 \dagger}$, Minkyung Kang ${ }^{1,3 \dagger}$, Jinsil Park ${ }^{1,5}$, Sung-Hye Park ${ }^{4,5}$ and Yong-Seok Lee ${ }^{1,3,5^{*}}$ (D)

\begin{abstract}
Neurofibromatosis type 1 (NF1) is an autosomal dominant disease caused by loss-of-function mutations in NF1 gene, which encodes a GTPase activating protein for RAS. NF1 affects multiple systems including brain and is highly associated with cognitive deficits such as learning difficulties and attention deficits. Previous studies have suggested that GABAergic inhibitory neuron is the cell type primarily responsible for the learning deficits in mouse models of NF1. However, it is not clear how NF1 mutations selectively affect inhibitory neurons in the central nervous system. In this study, we show that the expression level of $N f 1$ is significantly higher in inhibitory neurons than in excitatory neurons in mouse hippocampus and cortex by using in situ hybridization. Furthermore, we also found that NF1 is enriched in inhibitory neurons in the human cortex, confirming that the differential expressions of NF1 between two cell types are evolutionarily conserved. Our results suggest that the enriched expression of NF1 in inhibitory neurons may underlie inhibitory neuron-specific deficits in NF1.
\end{abstract}

Keywords: Neurofibromatosis type 1, Neurofibromin, Inhibitory neurons, RAS

Neurofibromatosis type 1 (NF1) is an autosomal dominant disorder caused by loss of function mutations in NF1 gene, which occurs in approximately 1 of 3000 births [1]. NF1 affects multiple organs, mainly skin, bone, and brain, and is diagnosed by café-au-lait spots, neurofibromas, optic glioma, Lisch nodules in iris, bone malformations [1-3]. NF1 is most abundantly expressed in the nervous system [4]. Subsequently, a wide range of cognitive deficits is associated with NF1, which include deficits in visuospatial perception, executive functioning, attention, social function and learning [5-7]. NF1 gene encodes neurofibromin (NF1) which is a GTPaseactivating protein (GAP) for RAS [8-10]. Thus, loss of function mutations in NF1 gene cause increases in the activation of RAS and its downstream signaling cascades [11]. Studies using mouse models of NF1 have shown that the enhanced activation of RAS-extracellular signal-related kinase (ERK)

\footnotetext{
* Correspondence: yongseok7@snu.ac.kr

${ }^{+}$Hyun-Hee Ryu and Minkyung Kang contributed equally to this work

1 Department of Physiology, Seoul National University College of Medicine, Seoul 03080, Korea

${ }^{3}$ Department of Biomedical Sciences, Seoul National University College of Medicine, Seoul 03080, Korea

Full list of author information is available at the end of the article
}

signaling is responsible for the learning deficits in NF1 [11-14]. Nf1 heterozygous knockout mice showed deficits in spatial learning and working memory, which can be rescued by attenuating RAS activation [12, 14]. Interestingly, elegant studies by Silva and colleagues have shown that gammaaminobutyric acidergic (GABAergic) inhibitory synaptic function is altered in both hippocampus and cortex of $\mathrm{Nf1}^{+/-}$mice $[12,13,15]$. To define the cell type responsible for the learning deficits in $\mathrm{Nf1}^{+/-}$ mice, Cui and colleagues deleted Nf1 selectively in excitatory neurons, inhibitory neurons, or glia and found that deleting $N f 1$ only in inhibitory neurons can recapitulate behavioral and cellular phenotypes shown in $\mathrm{Nf1}^{+/-}$mice such as deficits in spatial learning and long-term synaptic plasticity [13]. Since NF1 was shown to be ubiquitously expressed in adult neurons, oligodendrocytes, and Schwann cells $[4,16]$, it is intriguing that deleting $N f 1$ selectively affect inhibitory neurons. Recently, we have shown that the genes in RAS-ERK signaling network are differentially expressed between excitatory and inhibitory neurons in mouse hippocampus by performing cell type-specific transcriptome analyses [17]. Interestingly, $N f 1$ expression was found to be higher 
in vesicular gamma-aminobutyric acid transporter (vGAT)-positive neurons than in alpha $\mathrm{Ca}^{2+} / \mathrm{cal}-$ modulin-dependent kinase II ( $\alpha$ CaMKII)-positive neurons in mouse hippocampus by using cell typespecific RNA-sequencing (RNA-seq) analysis [17], which suggest that inhibitory neuron-enriched expression of NF1 may underlie the cell type-specific pathophysiology of NF1.

To confirm the expression pattern of $N f 1$ in mouse brain (male $\mathrm{C} 57 \mathrm{Bl} / 6 \mathrm{~J}, 7-8$ weeks) by using a different method, we performed fluorescent in situ hybridization. We used a gene-specific probe for mouse Nf1 together with probes for $\alpha$ CamkII and $v G A T$ as markers for excitatory and inhibitory neurons, respectively. Consistent with the previous RNA-seq result [17], we found that the Nf1 expression level is significantly higher in inhibitory neurons than in excitatory neurons in the mouse hippocampus (Fig. 1a and b). The area of Nf1 mRNA particles in $v G A T^{+}$neurons were significantly larger than in $\alpha \mathrm{CamkII}^{+}$neurons in hippocampal CA1 region (Area of Nf1 particles: $\alpha$ CamkII $^{+}, 3.97 \pm 0.16 \mu \mathrm{m}^{2} ; \nu G A T^{+}$, $8.25 \pm 1.24 \mu \mathrm{m}^{2}$; unpaired t-test, ${ }^{* * * * *} p<0.0001$; Fig. 1a and b). Next, we examined the expression of $N f 1$ in mouse cortex (Fig. 1c and d). As in the hippocampus, total area of Nf1 mRNA particles were bigger in $v G A T^{+}$neurons than in $\alpha C a m K I I^{+}$neurons in the parietal cortex (Area of Nf1 particles: $\alpha$ CamkII , $3.21 \pm 0.21 \mu \mathrm{m}^{2} ; v G A T^{+}, \quad 6.1 \pm 0.46 \mu \mathrm{m}^{2}$; unpaired $\mathrm{t}$ test, ${ }^{* * * *} p<0.0001$; Fig. $1 \mathrm{c}$ and d). Thus, these results show that the Nf1 is enriched in $v G A T^{+}$inhibitory neurons in the mouse hippocampus and cortex, which are hubs of spatial learning and higher-level executive brain function. This inhibitory neuronenriched expression of Nf1 might explain how inhibitory synaptic function is selectively affected in Nf1 mutant mice.

To verify that NF1 expression is also higher in inhibitory neurons than in excitatory neurons in human, we examined the NF1 mRNA expression in human cortex. Since the human tissues showed strong auto-fluorescent signals probably due to the fix condition, we used dual color chromogenic in situ hybridization system: NF1 was co-stained with either $\alpha$ CaMKII (also known as CaMK2A) or vGAT (also known as SL32A1). We used cortical biopsy samples from two human subjects who underwent surgery for focal cortical dysplasia type I. Normal cortical tissues around the affected area were used in this study. As previously reported [18], NF1 was detected in neurons in human brains (Fig. 1e and g). To examine whether NF1 is also enriched in inhibitory neurons in human, we analyzed the area of NF1 mRNA particle in $v G A T^{+}$or $\alpha C a M K I I^{+}$neurons.
Consistent with our finding in mouse cortex, area of human NF1 particle in each cell was also significantly larger in $v G A T^{+}$neurons than in $\alpha \mathrm{CaMKII}$ neurons in both samples (Area of NF1 particles: \#20399, $\alpha$ CamkII $^{+}, 10.31 \pm 0.4 \mu \mathrm{m}^{2} ; v G A T^{+}, 12.14 \pm$ $0.74 \mu \mathrm{m}^{2}$; unpaired t-test, " $p<0.0001$; \#17490, $\alpha$ Cam$k I I^{+}, 10.21 \pm 0.48 \mu \mathrm{m}^{2} ; v G A T^{+}, 15.76 \pm 0.98 \mu \mathrm{m}^{2}$; unpaired t-test, " $p<0.0001$; Fig. 1f and h). Collectively, we found that NF1 mRNA is enriched in $v G A T^{+}$ neurons compared to $\alpha C a M K I I^{+}$neurons both in mouse and human brain. Importantly, hybridizations using a negative control probe targeting a bacterial gene dihydrodipicolinate reductase (DapB) did not show any nonspecific background signal in mouse and human cortex (Additional file 1: Figure S1). To further examine the specificity of the probes, we performed cross-species hybridization experiments in which we used the mouse $N f 1$ probe on human tissue and the human NF1 probe on mouse tissue. We detected almost no signals compared to those from species-matching conditions (Additional file 1: Figure S1).

Initially, Costa and colleagues found that monosynaptically evoked inhibitory postsynaptic potentials are significantly larger in $\mathrm{NfI}^{+/-}$mice compared to those in wild type littermates, which was reversed by reducing Ras activity, showing that Nf1 deletion increases synaptic inhibition through Ras activation [12]. Later, Cui and colleagues showed that neurofibromin regulates ERK and synapsin phosphorylation in GABAergic neurons [13]. However, it is not clear how neurofibromin mainly regulates inhibitory synaptic functions. Recently, Omrani and colleagues showed that neurofibromin interacts with hyperpolarizationactivated cyclic nucleotide-gated ( $\mathrm{HCN})$ channel which is enriched in parvalbumin (PV)-expressing interneurons [19]. HCN current is selectively reduced in PV-expressing interneurons, resulting in hyperexcitability in PV-expressing inhibitory neurons both in $\mathrm{NI}^{+/-}$and $N f 1^{9 a-/ 9 a-}$ mice in which the neuronspecific exon 9 is deleted, which may contribute to inhibitory neuron-specific phenotypes in NF1 mouse models [19].

In our previous study, we showed that major components in RAS-ERK signaling pathway including $N f 1$ are differentially expressed between excitatory and inhibitory neurons in mouse hippocampus, proposing that this cell type-specific distribution of signaling molecules may underlie cell type selective pathophysiology observed in NF1 and other Rasopathies such as Noonan syndrome [17]. The expression pattern of NF1 has been extensively studied both in rodents and human brains, which have revealed that NF1 is expressed in neurons, oligodendrocytes, and Schwann 


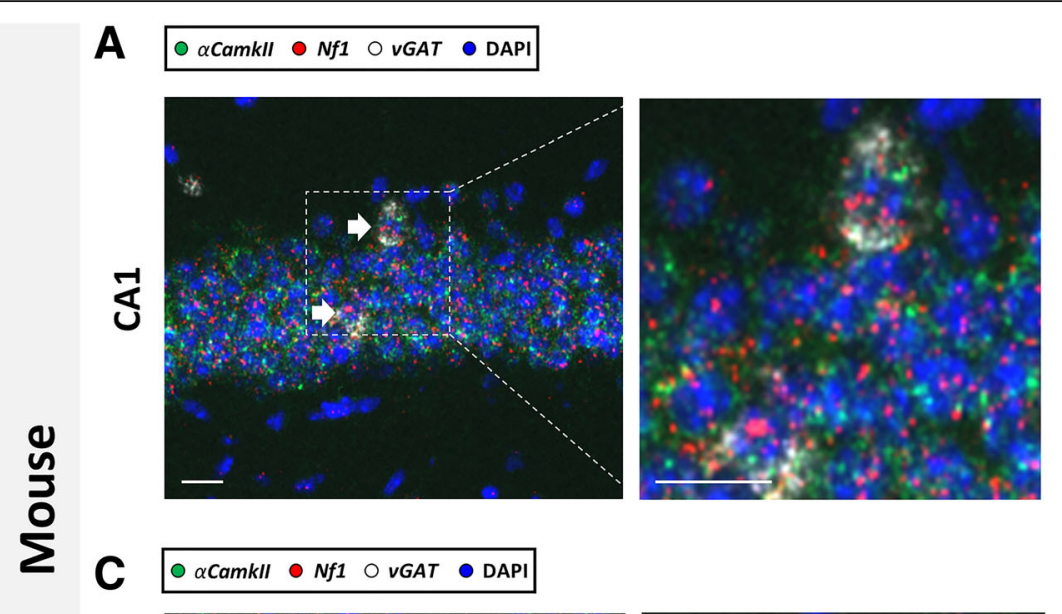

B
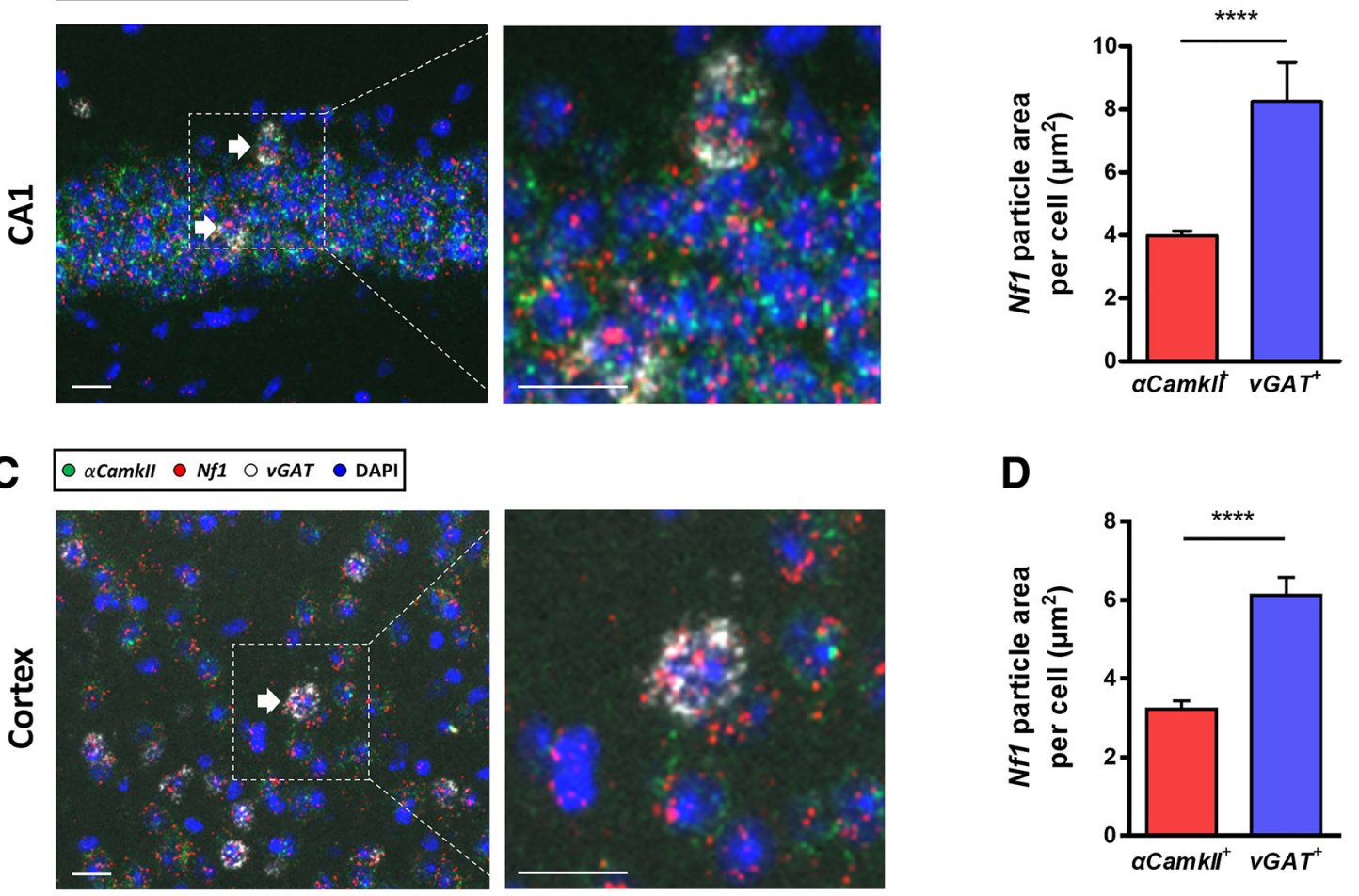

E
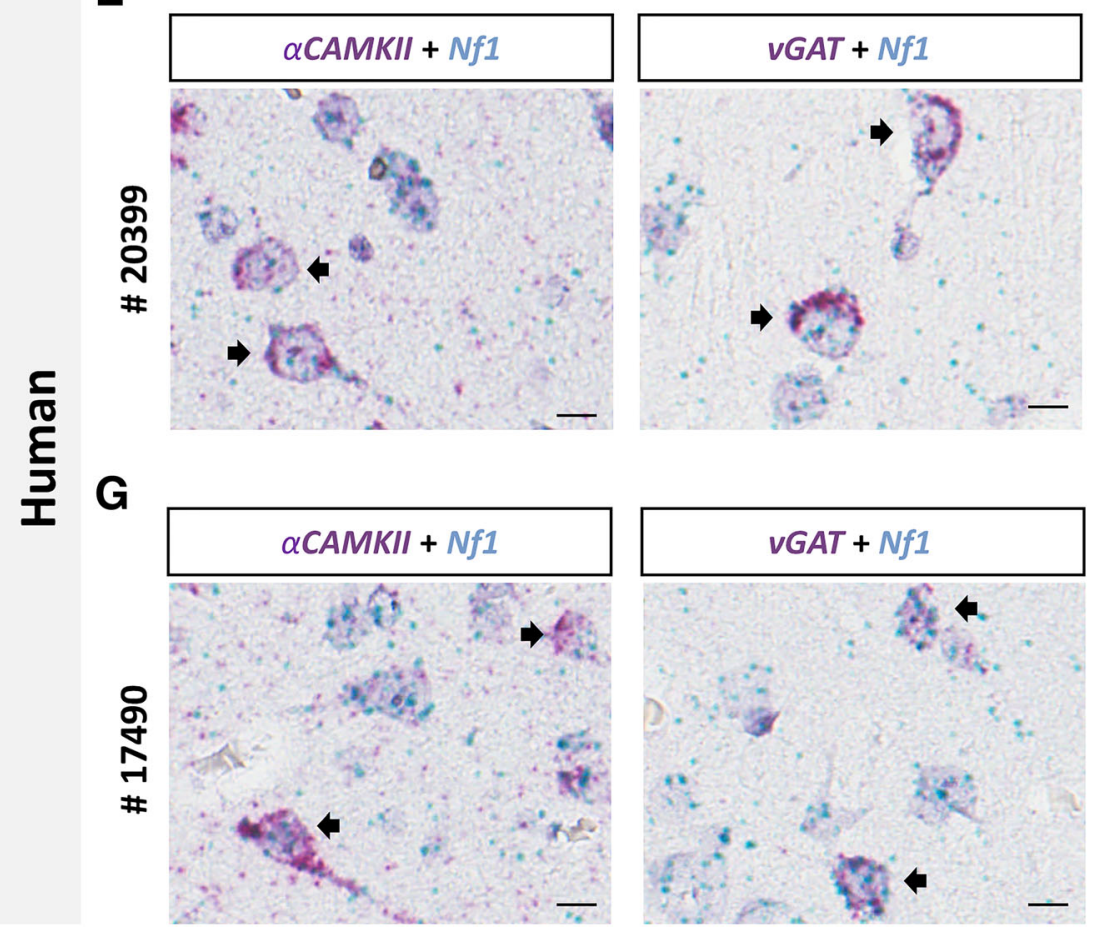

F

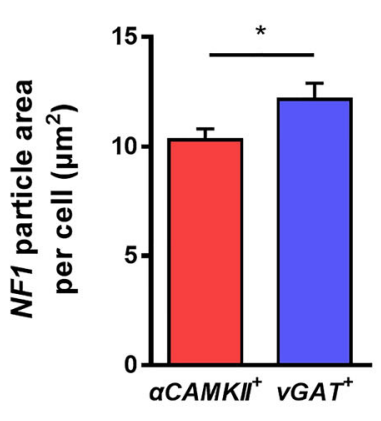

H

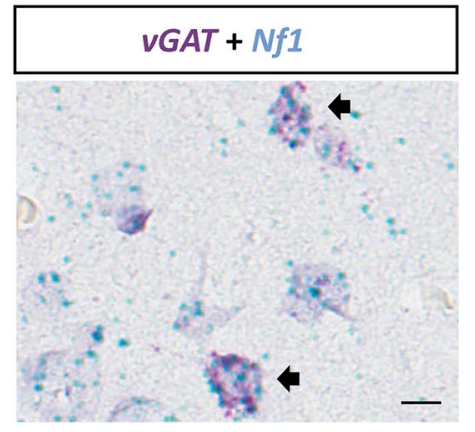

Fig. 1 (See legend on next page.)

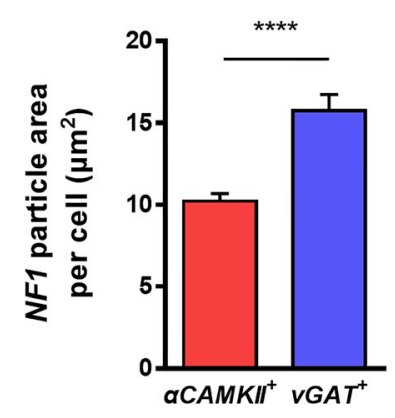


(See figure on previous page.)

Fig. 1 In situ hybridization of Nf1 in mouse and human brain. a Representative merged image of triple fluorescent in situ hybridization probed for Nf1 (red), aCamkll (green) and VGAT (white) in hippocampal CA1 region. Higher-magnification images of the boxed area in (a) were also shown. White arrows indicate double-positive cells for Nf1 and vGAT. Sections were also stained with DAPI (blue). In situ hybridization was performed following the manufacturers' manual (RNAscope Multiplex Fluorescent Reagent Kit, Advanced Cell Diagnostics) and the following probes (Advanced Cell Diagnostics) were used: mouse Nf1, catalog \#417351; mouse Slc32a1-C2, \#319191-C2; mouse CamK2-C3, \#445231-C3. Images were acquired by using Axio scan Z1 (Zeiss) and analyzed by using ImageJ (NIH). Scale bar, $10 \mu \mathrm{m}$. b Average particle size in aCamkll ${ }^{+}$neurons or vGAT ${ }^{+}$neurons in CA1. Data were collected from $627 \mathrm{aCamk \| ^{+ }}$ cells and $76 \mathrm{VGAT^{+ }}$ cells in hippocampal CA1 area. c Representative merged image of triple fluorescent in situ hybridization probed for Nf1 (red), aCamkll (green) and vGAT (white) in the perietal cortex. Scale bar, $10 \mu \mathrm{m}$. $\mathbf{d}$ Average particle size in aCaMKII ${ }^{+}$neurons or vGAT ${ }^{+}$neurons in

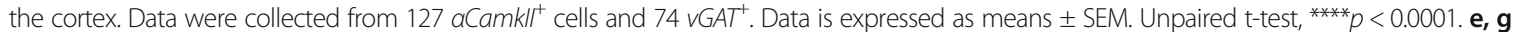
Representative merged image of duplex chromogenic in situ hybridization probed for NF1 (blue) and aCaMKII (red) or NF1 (blue), VGAT (red) and hematoxylin for counter-staining (light-purple color) in human cortex [e, sample \#20399, 3 years old female diagnosed with focal cortical dysplasia type I (temporal cortex); g sample \#17490, 2 years old male diagnosed with focal cortical dysplasia type I (frontal cortex)]. Black arrows indicate co-stained cells for either NF1 and aCaMKII or NF1 and VGAT. Chromogenic detection methods according to the manufacture's instruction (RNAscope duplex chromogenic detection Kit, Advanced Cell Diagnostics). Gene specific probes for human NF1, aCAMKII, and VGAT (human NF1, catalog \# 419731; human SLC32A1-C2, \#415681-C2; human CAMK2-C2, \#521261-C2) were used. Images were acquired by using Aperio scan (Leica Biosystems) and analyzed by using ImageJ $(\mathrm{NIH})$. Images were separated into 3 determined colors (red, green and blue) by 'colour deconvolution' plugin which transforms multiplecolor images into separated single color channels. Scale bar, $10 \mu \mathrm{m}$. $\mathbf{f}$ and $\mathbf{h}$ Average NF1 particle size in aCaMKII neurons or VGAT ${ }^{+}$neurons from \#20399 or \#17490. Data were collected from 99 aCaMKII cells and 92 vGAT cells in \#20399; 142 aCaMKII cells and 98 vGAT cells in \#17490. Data is expressed as means \pm SEM. Unpaired t-test, ${ }^{*} p<0.01,{ }^{* * *} p<0.001$

cells, and even astrocytes depending on the conditions and the isoforms [4, 16, 18, 20-22]. However, it was not clear in which neuronal type NF1 is enriched. Our results clearly demonstrate that NF1 is enriched in inhibitory neuron in mouse and human brain. Specific inhibitory neuronal types in which NF1 is enriched remains to be determined. Taken together, our results strongly suggest that the cell type-specific RAS-ERK signaling networks might be, at least for several molecules, evolutionarily conserved between mouse and human and therefore, the mechanisms for cognitive deficits revealed in NF1 mouse models may turn out to be also true in human NF1.

\section{Additional file}

Additional file 1: Figure S1. Representative image of in situ hybridization by using a negative control probe or cross-species probes in human and mouse cortex. (A-B) Human (A) or mouse (B) cortex samples were hybridized with a probe targeting $D a p B$ by using a fluorescent or chromogenic hybridization method, respectively. No DapB signal (blue in A, red in B) was detected. Slices were counter-stained with hematoxylin or DAPI. (C-D) Cross-species hybridization. (C) Human cortex sample was hybridized with the mouse Nf1 probe (blue). (D) Mouse cortex sample was hybridized with the human NF1 probe (blue). Slices were counter-stained with hematoxylin. Scale bars, $50 \mu \mathrm{m}$. (PDF $131 \mathrm{~kb}$ )

\section{Abbreviations}

ERK: Extracellular signal-regulated kinases; GABAergic: Gamma-aminobutyric acidergic; GAP: GTPase-activating protein; HCN: Hyperpolarization-activated cyclic nucleotide-gated channel; NF1: Neurofibromatosis type I; PV: Parvalbumin; RNA-seq: RNA-sequencing; VGAT: Vesicular gamma-aminobutyric acid transporter; aCaMKII: Alpha $\mathrm{Ca}^{2+} /$ calmodulin-dependent kinase II

Acknowledgements

Not applicable.

\section{Authors' contributions}

Y-SL designed and supervised the study. H-HR, MK, JP performed the experiments. S-HP prepared and provided human brain tissues. Y-SL, H$H R$ and MK wrote the manuscript. All authors read and approved the final manuscript.

\section{Funding}

This work was supported by NRF-2016R1E1A1A01941939, NRF2017M3C7A1026959, NRF-2019R1A4A2001609 to Y.-S.L.; NRF-

2016H1A2A1907206 to M.K.

\section{Availability of data and materials}

All data generated or analyzed during this study are included in this published article.

\section{Ethics approval and consent to participate}

Animal study was approved by the Institutional Animal Care and Use Committees at Seoul National University. Human cortical tissues were obtained from archives of Department of Pathology, Seoul National University Hospital and this study was approved by the Institutional Review Board at Seoul National University Hospital (1712-086-907).

\section{Consent for publication}

Not applicable.

\section{Competing interests}

The authors declare that they have no competing interests.

\section{Author details}

'Department of Physiology, Seoul National University College of Medicine, Seoul 03080, Korea. ${ }^{2}$ Department of Life Science, Chung-Ang University, Seoul 06974, Korea. ${ }^{3}$ Department of Biomedical Sciences, Seoul National University College of Medicine, Seoul 03080, Korea. ${ }^{4}$ Department of Pathology, Seoul National University Hospital, Seoul 03080, Korea. ${ }^{5}$ Neuroscience Research Institute, Seoul National University College of Medicine, Seoul 03080, Korea.

Received: 13 May 2019 Accepted: 17 June 2019

Published online: 24 June 2019

\section{References}

1. Upadhyaya M, Cooper DN. Neurofibromatosis type 1 : molecular and cellular biology. Berlin. New York: Springer; 2012.

2. DeBella K, Szudek J, Friedman JM. Use of the national institutes of health criteria for diagnosis of neurofibromatosis 1 in children. Pediatrics. 2000;105:608-14. 
3. Gutmann DH, Aylsworth A, Carey JC, Korf B, Marks J, Pyeritz RE, Rubenstein A, Viskochil $D$. The diagnostic evaluation and multidisciplinary management of neurofibromatosis 1 and neurofibromatosis 2. JAMA. 1997;278:51-7.

4. Daston MM, Ratner N. Neurofibromin, a predominantly neuronal GTPase activating protein in the adult, is ubiquitously expressed during development. Dev Dyn. 1992;195:216-26.

5. Hyman SL, Shores A, North KN. The nature and frequency of cognitive deficits in children with neurofibromatosis type 1. Neurology. 2005;65:1037-44.

6. Chisholm AK, Anderson VA, Pride NA, Malarbi S, North KN, Payne JM. Social function and autism Spectrum disorder in children and adults with Neurofibromatosis type 1: a systematic review and meta-analysis. Neuropsychol Rev. 2018;28:317-40.

7. Krab LC, Aarsen FK, de Goede-Bolder A, Catsman-Berrevoets CE, Arts WF Moll HA, Elgersma Y. Impact of neurofibromatosis type 1 on school performance. J Child Neurol. 2008:23:1002-10.

8. Ballester R, Marchuk D, Boguski M, Saulino A, Letcher R, Wigler M, Collins F. The NF1 locus encodes a protein functionally related to mammalian GAP and yeast IRA proteins. Cell. 1990;63:851-9.

9. Martin GA, Viskochil D, Bollag G, McCabe PC, Crosier WJ, Haubruck H, Conroy L, Clark R, O'Connell P, Cawthon RM, et al. The GAP-related domain of the neurofibromatosis type 1 gene product interacts with ras p21. Cell. 1990;63:843-9

10. Xu GF, Lin B, Tanaka K, Dunn D, Wood D, Gesteland R, White R, Weiss R, Tamanoi $F$. The catalytic domain of the neurofibromatosis type 1 gene product stimulates ras GTPase and complements ira mutants of S. cerevisiae. Cell. 1990;63:835-41.

11. Shilyansky C, Lee YS, Silva AJ. Molecular and cellular mechanisms of learning disabilities: a focus on NF1. Annu Rev Neurosci. 2010;33:221-43.

12. Costa RM, Federov NB, Kogan JH, Murphy GG, Stern J, Ohno M, Kucherlapati $\mathrm{R}$, Jacks T, Silva AJ. Mechanism for the learning deficits in a mouse model of neurofibromatosis type 1. Nature. 2002:415:526-30.

13. Cui Y, Costa RM, Murphy GG, Elgersma Y, Zhu Y, Gutmann DH, Parada LF, Mody I, Silva AJ. Neurofibromin regulation of ERK signaling modulates GABA release and learning. Cell. 2008;135:549-60.

14. Li W, Cui Y, Kushner SA, Brown RA, Jentsch JD, Frankland PW, Cannon TD, Silva AJ. The HMG-CoA reductase inhibitor lovastatin reverses the learning and attention deficits in a mouse model of neurofibromatosis type 1. Curr Biol. 2005;15:1961-7.

15. Shilyansky C, Karlsgodt KH, Cummings DM, Sidiropoulou K, Hardt M, James AS, Ehninger D, Bearden CE, Poirazi P, Jentsch JD, et al. Neurofibromin regulates corticostriatal inhibitory networks during working memory performance. Proc Natl Acad Sci U S A. 2010;107:13141-6.

16. Gutmann DH, Geist RT, Wright DE, Snider WD. Expression of the neurofibromatosis 1 (NF1) isoforms in developing and adult rat tissues. Cell Growth Differ. 1995;6:315-23.

17. Ryu H-H, Kim T, Kim J-W, Kang M, Park P, Kim YG, Kim H, Ha J, Choi JE, Lee J, et al. Excitatory neuron-specific SHP2-ERK signaling network regulates synaptic plasticity and memory. Sci Signal. 2019;12:eaau5755.

18. Nordlund ML, Rizvi TA, Brannan Cl, Ratner N. Neurofibromin expression and astrogliosis in neurofibromatosis (type 1) brains. J Neuropathol Exp Neurol. 1995:54:588-600.

19. Omrani A, van der Vaart T, Mientjes E, van Woerden GM, Hojjati MR, Li KW, Gutmann DH, Levelt CN, Smit AB, Silva AJ, et al. HCN channels are a novel therapeutic target for cognitive dysfunction in Neurofibromatosis type 1. Mol Psychiatry. 2015;20:1311-21.

20. Geist RT, Gutmann DH. Expression of a developmentally-regulated neuronspecific isoform of the neurofibromatosis 1 (NF1) gene. Neurosci Lett. 1996; 211:85-8.

21. Gutmann DH, Zhang $Y$, Hirbe A. Developmental regulation of a neuronspecific neurofibromatosis 1 isoform. Ann Neurol. 1999;46:777-82.

22. Hewett SJ, Choi DW, Gutmann DH. Expression of the neurofibromatosis 1 (NF1) gene in reactive astrocytes in vitro. Neuroreport. 1995;6:1565-8.

\section{Publisher's Note}

Springer Nature remains neutral with regard to jurisdictional claims in published maps and institutional affiliations.

\section{Ready to submit your research? Choose BMC and benefit from}

- fast, convenient online submission

- thorough peer review by experienced researchers in your field

- rapid publication on acceptance

- support for research data, including large and complex data types

- gold Open Access which fosters wider collaboration and increased citations

- maximum visibility for your research: over $100 \mathrm{M}$ website views per year

At $\mathrm{BMC}$, research is always in progress.

Learn more biomedcentral.com/submissions 